\title{
Negative Pregnancy Test—Can It Confidently Rule out an Ectopic?
}

\author{
Avni Batish \\ Princess Royal University Hospital, Kings College Hospital NHS Foundation Trust, London, UK \\ Email: avni batish@yahoo.co.in \\ Received 24 May 2014; revised 20 June 2014; accepted 15 July 2014 \\ Copyright @ 2014 by author and Scientific Research Publishing Inc. \\ This work is licensed under the Creative Commons Attribution International License (CC BY). \\ http://creativecommons.org/licenses/by/4.0/ \\ (c) (i) Open Access
}

\begin{abstract}
We have presented an unusual case of ectopic pregnancy with the negative urinary pregnancy test and a very low level of serum beta-hCG (11 IU/L). Ultrasound scan revealed right adnexal mass. Medical management and laparoscopic salpingectomy allowed for a favourable outcome.
\end{abstract}

\section{Keywords}

Ectopic Pregnancy, Methotrexate, Laparoscopic Salpingectomy, Chronic Ectopic Pregnancy

\section{Introduction}

Ectopic pregnancy is a common clinical pathology with possibly serious maternal morbidity and mortality. It remains the most common cause of maternal death in the first trimester accounting for $55 \%$ of early pregnancy deaths [1]. A qualitative urine dipstick test for beta-hCG (urinary pregnancy test) is a quick, easy, and sensitive diagnostic test. It has a sensitivity of $99 \%$ at a urine beta-hCG level greater than 25 IU/L [2]. In case of ectopic pregnancies, negative urine pregnancy test and negative serum beta-hCG are respectively recorded in $3.1 \%$ and $2.6 \%$ of the cases (Skinner \& Jones, 2003). Madu et al. (2004) noted that urine beta-hCG was negative in $2 \%$ of pregnancies and theories suggested were small masses of villi producing hormone, defective hormone biosynthesis and production, improved renal clearance of hormone or due to the test kit. Review of the published work indicates a consensus that, whatever the site of pregnancy, a falling serum beta-hCG concentration justifies expectant management [3]. In the present case the low and falling serum beta-hCG suggested that the pregnancy was unlikely to be an ectopic pregnancy [4].

\section{Case Report}

The patient was 44 years old and in her second pregnancy. She presented to the early pregnancy unit at 8 weeks gestation with vaginal bleeding. Transvaginal ultrasound scan (TVS) revealed a normal size uterus with an en- 
dometrium that was $16 \mathrm{~mm}$ thick. There was right adnexal tenderness with no mass, cysts or free fluid. The ovaries had a normal appearance. Serum beta-hCG on admission was 8307 IU/L. Repeat TVS 48 hours later revealed a $1.34 \mathrm{~cm} \times 1.4 \mathrm{~cm}$ sac like structure in the cervical region. As the beta-hCG was equivocal, the further management options offered to the patient were a laparoscopy or methotrexate administration. The latter was carried out in keeping with the patient's wish after ensuring normal liver and renal functions. Following this, the beta-hCG fell significantly over the subsequent two weeks to $378 \mathrm{IU} / \mathrm{L}$. TVS at the same time showed a $2.5 \mathrm{~cm}$ $\times 2.5 \mathrm{~cm} \times 3.5 \mathrm{~cm}$ mixed echogenic mass in relation to the right fallopian tube and ovary without any free fluid in the pelvis; indicating a possible unruptured ectopic pregnancy. On serial scans this mass was persistent and within the mass, there was a suggestion of a collapsed gestational sac. Urine pregnancy test was NEGATIVE. Serum beta-hCG was $11 \mathrm{IU} / \mathrm{L}$. In view of ultrasound findings and the patients' complaint of persistent moderate right iliac fossa pain, a laparoscopic right salpingectomy with excision of the mass was carried out. Laparoscopy confirmed right tubal ectopic with minimal amount of free fluid in the pelvis. Right salpingectomy was performed and specimen sent for histopathological examination. The histology confirmed right tubal ectopic pregnancy.

\section{Discussion}

The patient had a chronic ectopic pregnancy. Chronic ectopic pregnancy is a form of tubal pregnancy in which salient minor ruptures or abortions of an ectopic pregnancy occur instead of a single episode of bleeding. This incites an inflammatory response often leading to the formation of a pelvic mass. Its clinical features are often confusing, and laboratory evaluations often misleading. Surgery for chronic ectopic pregnancy is frequently difficult since chronic inflammatory changes and adhesions distort the normal anatomy [5]. One feature setting chronic ectopic pregnancy apart from acute ectopic pregnancy is the frequent presence of a mass on physical examination or ultrasound study [6] [7]. In addition, owing to the presence of nonviable trophoblast, a high incidence of negative pregnancy test results is often present [6] [7]. False-negative serum beta-hCG assays are found in $6.8 \%$ to $8 \%$ of cases [6]. Ectopic pregnancies associated with negative urine or serum pregnancy test by radioimmunoassay usually demonstrate either nonviable trophoblast or absent production of beta-hCG by the ectopic pregnancy [8]. Negative serum and urine pregnancy tests can occur even though beta-hCG produced by the viable ectopic trophoblastic tissue can be demonstrated by immunoperoxidase staining [8].

Gracia and Barnhart [9] compared different methods of diagnosing ectopic pregnancy using combinations of transvaginal ultrasound plus biochemistry (serum progesterone and serum beta-hCG), ultrasound only, and clinical examination without ultrasound. The study found that the most accurate method of diagnosing ectopic pregnancy was using a combination of ultrasound followed by beta-hCG.

\section{Conclusion}

This case illustrates the potential for an ectopic pregnancy to be missed with negative pregnancy test. Hence we should rely on serum beta-hCG instead of urine beta-hCG to prevent potential ectopic pregnancies being missed. Further, it demonstrates the helpful role of ultrasonography in diagnosing a patient with ectopic.

\section{References}

[1] (2011) Saving Mothers’ Lives: Reviewing Maternal Deaths to Make Motherhood Safer: 2006-2008. BJOG: An International Journal of Obstetrics \& Gynaecology, 118, 1-203. http://dx.doi.org/10.1111/j.1471-0528.2010.02847.x

[2] Condous, G. (2006) Ectopic Pregnancy—Risk Factors and Diagnosis. Australian Family Physician, 35, 854-857.

[3] Ankum, W.M., Van der Veen, F., Hamerlynck, J.V.T. and Lammes, F.B. (1995) Suspected Ectopic Pregnancy-What to Do When Human Chorionic Gonadotrophin Levels Are below the Discriminatory Zone. Journal of Reproductive Medicine, 40, 525-528.

[4] Dart, R.G., Mitterando, J. and Dart, L.M. (1999) Rate of Change of Serial Beta Human Chorionic Gonadotrophin Values as a Predictor of Ectopic Pregnancy in Patients with Indeterminate Transvaginal Scan Findings. Annals of Emergency Medicine, 34, 707-710. http://dx.doi.org/10.1016/S0196-0644(99)70094-6

[5] Ugur, M., Turan, C., Vicdan, K., Ekici, E., Oguz, O. and Gokmen, O. (1996) Chronic Ectopic Pregnancy: A Clinical Analysis of 62 Cases. Australian and New Zealand Journal of Obstetrics and Gynaecology, 36, 186-189. http://dx.doi.org/10.1111/j.1479-828X.1996.tb03283.X 
[6] Cole, T. and Corlett Jr., R.C. (1982) Chronic Ectopic Pregnancy. Obstetrics \& Gynecology, 59, 63-68.

[7] Bedi, D.G., Moeller, D., Fagan, C.J. and Winsett, M.Z. (1987) Chronic Ectopic Pregnancy. A Comparison with Acute Ectopic Pregnancy. European Journal of Radiology, 7, 46-48.

[8] Maccato, M.L., Estrada, R. and Faro, S. (1993) Ectopic Pregnancy with Undetectable Serum and Urine $\beta$ hCG Levels and Detection of, $\beta \mathrm{hCG}$ in the Ectopic Trophoblast by Immunocytochemical Evaluation. Obstetrics and Gynecology, 81, 878-880.

[9] Gracia, C. and Barnhart, K. (2001) Diagnosing Ectopic Pregnancy: Decision Analysis Comparing Six Strategies. Obstetrics \& Gynecology, 97, 464-470. http://dx.doi.org/10.1016/S0029-7844(00)01159-5 
Scientific Research Publishing (SCIRP) is one of the largest Open Access journal publishers. It is currently publishing more than 200 open access, online, peer-reviewed journals covering a wide range of academic disciplines. SCIRP serves the worldwide academic communities and contributes to the progress and application of science with its publication.

Other selected journals from SCIRP are listed as below. Submit your manuscript to us via either submit@scirp.org or Online Submission Portal.
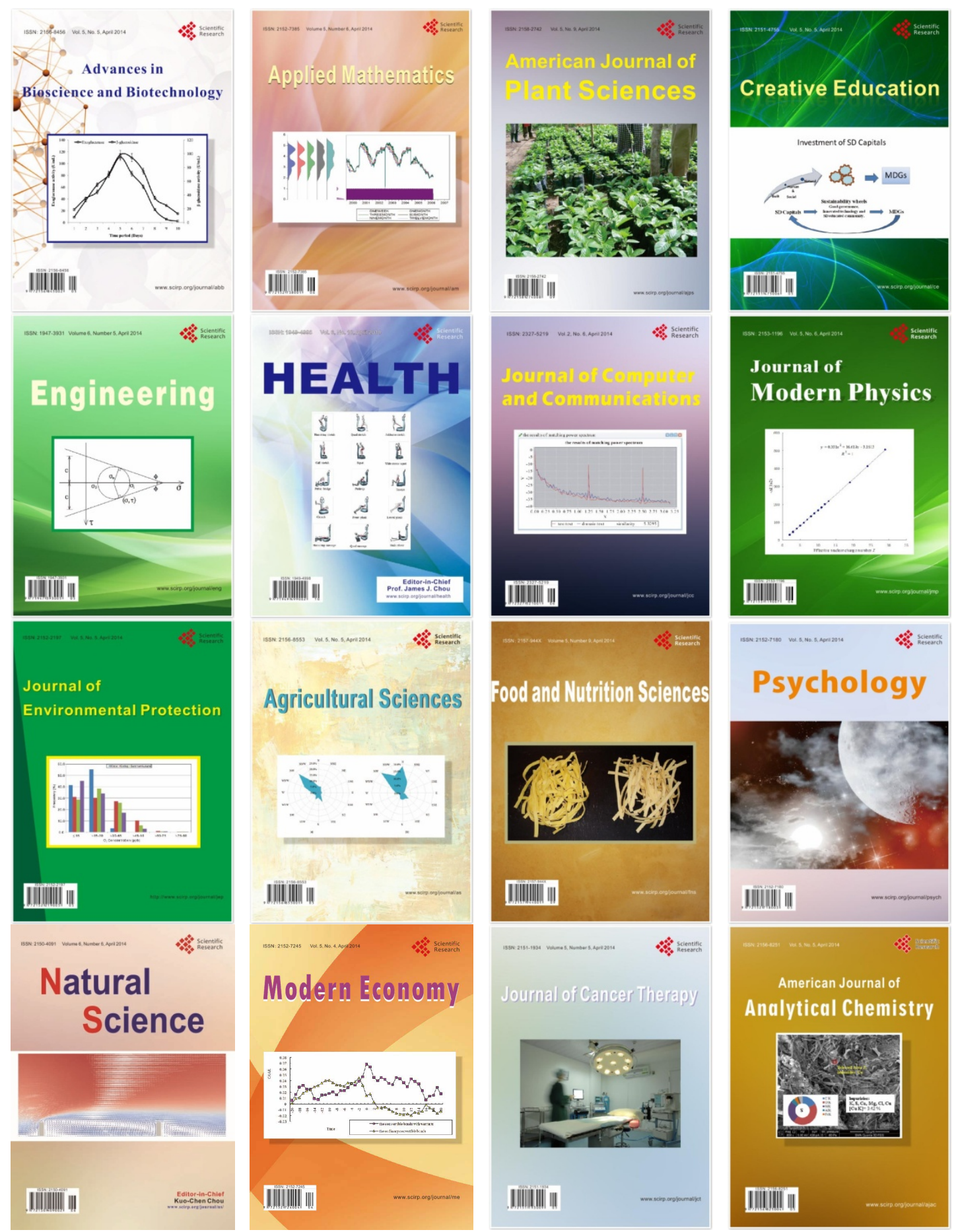